AAM

11,3

200

Received 18 January 2021

Revised 23 April 2021

Accepted 7 June 2021

\section{Artists as cultural intermediaries? Remediating practices of production and consumption}

\author{
Steven Hadley \\ Moore Institute, National University of Ireland Galway, Galway, Ireland
}

\begin{abstract}
Purpose - The purpose of this paper is to discuss findings from an Arts and Humanities Research Council (AHRC)-funded research project into the heritage culture of British folk tales. The project investigated how such archival source material might be made relevant to contemporary audience via processes of artistic remediation. The research considered artists as "cultural intermediaries", i.e. as actors occupying the conceptual space between production and consumption in an artistic process.

Design/methodology/approach - Interview data is drawn from a range of 1-2-1 and group interviews with the artists. These interviews took place throughout the duration of the project.

Findings - When artists are engaged in a process of remediation which has a distinct arts marketing/audience development focus, they begin to intermediate between themselves and the audience/consumer. Artist perceptions of their role as "professionals of qualification" is determined by the subjective disposition required by the market context in operation at the time (in the case of this project, as commissioned artists working to a brief). Artists' ability (and indeed willingness) to engage in this process is to a great extent proscribed by their "sense-of-self-as-artist" and an engagement with Romantic ideas of artistic autonomy.

Originality/value - A consideration of the relationship between cultural intermediation and both cultural policy and arts marketing. The artist-as-intermediary role, undertaking creative processes to mediate how goods are perceived by others, enables value-adding processes to be undertaken at the point of remediation, rather than at the stage of intermediation.
\end{abstract}

Keywords Cultural intermediaries, Arts marketing, Artist, Cultural production, Cultural consumption Paper type Research paper

All my big mistakes are when I try to second-guess or please an audience. My work is always stronger when I get very selfish about it. David Bowie quoted in Harrison (2016, n/a)

\section{Introduction}

This paper discusses findings from a research project into the heritage culture of British folk tales, which questioned how such source material might be made relevant to contemporary audience via processes of artistic remediation (Hadley et al., 2021). The AHRC-funded project, Modern Fairies, sought to actively place composition in its social context through involving audience and the commercial arts sector in a process designed to remediate heritage culture. The discussion presented here considers whether the artists involved in the project might be viewed as "cultural intermediaries" (Bourdieu, 1984) in an artistic process which mediated between professional(ised) and everyday cultural consumption and whether the process of artistic remediation (in the specific context of a commissioned, academic research project) might also be considered a process of intermediation.

(C) Steven Hadley. Published by Emerald Publishing Limited. This article is published under the Creative Commons Attribution (CC BY 4.0) licence. Anyone may reproduce, distribute, translate and create derivative works of this article (for both commercial and non-commercial purposes), subject to full attribution to the original publication and authors. The full terms of this licence may be seen at http:// creativecommons.org/licences/by/4.0/legalcode 
Given that the specificity of artistic production has long been acknowledged (Hirschman, 1983), the paper asks whether it is legitimate, within the extended discourse on "cultural intermediaries" which has evolved since Bourdieu's (1984) initial elaboration (Negus, 2002; O'Brien et al., 2011) to consider artists as "cultural intermediaries", i.e. as actors occupying the conceptual space between production and consumption in an artistic process. Such a positioning calls into question the idea of "sense-of-self-as-artist", a material and discursive position which has been much debated alongside significant digital shifts in the music industry (Musgrave, 2015).

If, as Bilton (2017) argues, traditional intermediaries in the creative industries (publishers, broadcasters, record labels and film studios) have been replaced by a new generation of intermediaries from the technology sector, within this still developing model, cultural producers and cultural products have been both displaced and devalued. The Modern Fairies research project, both via its aims as per the original funding application and the briefings given to artists, specifically sought to engage the artists in both debate and praxis as regards remediating original folkloric source material in such a way as to make it "relevant to modern audiences" (Modern Fairies, 2020). Such an approach brought the artists into negotiation both with their sense-of-self-as-artist in the context of market economics, and as "Artists" who aspired to varying degrees to retain a degree of emancipation (both moral and financial) from the messy business of late-stage capitalism and the transitioning of business models within the recorded, published and live performance cultural industries.

To consider these conceptualisations, the paper analyses research data regarding both the artists' "sense-of-self" and their self-conceptualisation as artists working as both performer and researcher within the project, and their negotiations of agency and autonomy within a proscribed research process. This analysis is situated within two distinct contexts. Firstly, the Romantic idea that artists "create primarily to express their subjective conceptions of beauty, emotion or some other aesthetic ideal" (Fillis, 2011, p. 15) such that aesthetic forms of creativity are the determining factor in the creative process (Becker, 1982; Holbrook, 1981), as opposed to a consideration of market need/demand (Holbrook and Zirlin, 1983; Hirschman, 1983). Secondly, the apparent contradiction in the central tenet of arts marketing as both a body of theory and a management practice in the subsidised cultural sector. Namely, that practices of audience development generally adopt market-led practice in an avowedly product-led sector, or as Lee (2005a, p. 7) describes it, attempt to reconcile/accept "producer authority over market demand".

The paper begins with an overview of some relevant conceptualisations of cultural intermediaries, particularly as regards the arts sector. This is followed by a brief consideration of the relationship between cultural intermediation and both cultural policy and arts marketing. A short outline of the Modern Fairies project precedes a discussion of interview data from the project, which is drawn from a range of 1-2-1 and group interviews with the artists which were undertaken throughout the duration of the project. The paper concludes with some reflections on the contested nature of cultural production and consumption from the perspective of creative artists-as-intermediaries. This paper does not attempt to sit within a particular literature but is rather a reflective account of a multidisciplinary research project which similarly adopts a multi-disciplinary perspective to frame the research method and elucidate the findings. As such, the narrative dominates over any methodological insight.

\section{Cultural intermediaries}

An influential concept in theoretical and empirical research on the cultural and creative industries, the concept of "cultural intermediaries" - those actors occupying the conceptual space between production and consumption - was identified by Bourdieu (1984) as
Practices of production and consumption 
AAM 11,3 strategically significant in the delineation of the field of culture. In Bourdieu's initial conceptualisation (1984, p. 359), the practice of cultural intermediation "comes into its own in all the occupations (sales, marketing, advertising, public relations, fashion, decoration and so forth) and in all the institutions providing symbolic goods and services”. Cultural intermediaries thereby operated in the space between production and consumption, presentation and representation. Their role, at the intersection of culture and economy, being to mediate how goods are perceived by others.

The field of cultural intermediary research is profuse and diverse with the field's conceptual frameworks and methodological foundations enabling a diverse array of empirical research (Smith Maguire and Matthews, 2014) despite the concern that some uses of the concept differ from Bourdieu's original intentions (Negus, 2002; Hesmondhalgh, 2006). Informed by research in fields such as cultural sociology, arts management and cultural economics, academic work on cultural intermediaries has tended to focus on specific occupational activity (often as new occupations come into being) and to a greater extent on the relationships between cultural intermediaries within commodity chains (processes used to gather resources, transform them into goods/commodities and distribute them to consumers) and cultural fields (Smith Maguire, 2015). Typically, empirical accounts of cultural intermediaries locate their activity between the moments of production and consumption, as "professionals of qualification" (Callon et al., 2002, p. 206) who operate on the supply side of the market to intervene in how consumers perceive and engage with goods. Through performing a range of actions in the production and promotion of consumption of cultural goods, they sought to frame those goods as culturally legitimate, thereby adding symbolic value to them via qualification. In the context of the Modern Fairies project, this paper adopts a wide-angle lens to consider cultural intermediaries as defined by what they do rather than being conceptualised as belonging to a particular socio-occupational group (Smith Maguire and Matthews, 2010, 2012).

To acknowledge the varied work that populates this field an operational definition of cultural intermediaries at work in the production of meaning must first recognise that they are "market actors who construct value by mediating how goods (or services, practices, people) are perceived and engaged with by others (end consumers, and other market actors including cultural intermediaries)" (Mathews and Smith Maguire, 2014, p. 2). Nonetheless, value construction through processes of mediation is a necessary yet not sufficient condition for identifying cultural intermediaries, who should equally be conceptualised via their expert orientation and market context:

In the struggle to influence others' perceptions and attachments, cultural intermediaries are defined by their claims to professional expertise in taste and value within specific cultural fields (and the foundations on which such claims rest). And, they are differentiated by their locations within commodity chains (vis-à-vis the actors and stages of cultural production they negotiate with and between, and the goods that they mediate), and by the autonomy, authority and arsenal of devices and resources that they deploy in negotiating structural and subjective constraints to accomplishing their agendas (Mathews and Smith Maguire, 2014, p. 2).

Although Hesmondhalgh (2006) suggests that "cultural intermediaries" may lack robustness as an analytic category, the concept has significant utility for understanding both the interconnections between the spheres of production and consumption and the role of artists in the Modern Fairies project. Data analysis later in the paper will show how the project artists work around-and through-ideas of cultural legitimacy, drawing upon their individual and shared (collaborative) cultural capital and dispositions to shape audience and fan community perceptions of, and preferences for, consumption of their cultural output.

Much work on this topic concerns itself with the conceptual and empirical specification of "the material practices, generic devices and subjective dispositions involved in cultural 
intermediary work" (Mathews and Smith Maguire, 2014, p. 7). It is the third of these criteriasubjective dispositions - which emerged as a key theme in the research data. Analysing the work of cultural production undertaken in the project through this lens provides insight into the extent to which Romantic notions of "the Artist" maintain influence on contemporary artistic practice, and further whether the material practices (as prescribed in the project brief) of the artists-as-intermediaries create a form of cognitive and/or creative dissonance with the adopted subjective disposition of/sense-of-self as "an Artist". As will be discussed, adherence to such a subjective disposition appears to be influenced by the market context of the creative process (commercial, subsidised and working to brief) and differing conceptualisations of the intended and/or desired audience.

\section{Cultural intermediation and cultural policy}

Cultural policy is the vehicle through which the state attempts to alter and affect the cultural consumption of both individual citizens and socio-demographic groups. As such, "cultural policy is a form of public policy... and it is subject to the same political changes, financial challenges and global tensions as any other form of public policy" (Bell and Oakley, 2015, p. 6). The cultural policy, therefore, has shifting interests, values and priorities depending on the geographical and political space it inhabits and the time frame in which it operates. This can (and very frequently does) mean that the subsidised arts are favoured as needing increases in volumes of consumption, whereas "It appears to be of no concern to policymakers if white, middle-class, educated individuals fail to engage with video games, nor the fact that those over 35 are more likely to be 'non-participants' of live rock and pop music" (Stevenson, 2013, p. 82). As Ultee et al. (1993, p. 173) argued, differentials of engagement in state-subsidised "high culture" are common to many nations such that cultural participation is "a socially unequally distributed phenomenon". This inexorably means that cultural policy "entails a redistribution of resources upwards, towards those who are already most privileged" (Miles and Sullivan, 2012, p. 321).

The problematisation of this lack of participation (the labelling of individuals as "cultural non-participants") is unquestioningly accepted by those trying to "target" and "engage" them. Cultural nonparticipants are represented as a "problem" category in binary contrast to those members of society who do participate (Stevenson, 2013). This problem is often attributed to (variously) a lack of availability, access, disposable income or diversity. However, there is a solid body of research showing that

social hierarchies and cultural hierarchies map closely onto each other. Individuals in higher social strata are those who prefer, and predominantly consume "elite" or "high" culture; and individuals in lower strata are those who prefer, and predominantly consume, "mass" or "popular" culture-with, perhaps, intermediate situations being also recognized (Wing Chan and Goldthorpe, 2007, p. 374).

This ideological basis of UK arts policy simultaneously entwines an ideological democratisation of culture and a product-led approach to cultural audience (Hadley, 2021). In this context, managerial practices of audience development generally adopt market-led practices in an avowedly product-led sector, or as Lee (2005a, p. 7) describes it, professional arts marketing processes attempt to reconcile/accept "producer authority over market demand". In this context, the cultural intermediary's role becomes one of enabling access into the arts for non-participant audience through practices such as arts marketing.

\section{Arts marketing}

For Bourdieu (1984), cultural intermediaries occupied (then) new professional roles involving the mediation of "legitimate" culture to the masses (O'Brien et al., 2011). While, in a UK 
AAM 11,3 context, a more sophisticated understanding of cultural engagement has evolved, it is nonetheless still the case that, "although cultural capital achieves its effects in a different and differentiated manner, clothed in an inclusive ethic, it still helps secure the reproduction of the privilege of the professional-executive class" (Bennett et al., 2009). In this scenario, the function of arts marketing (and more latterly audience development (Hadley, 2021) and audience engagement (Walmsley, 2019)) remains significant.

Actors in the cultural sector traditionally defined as intermediaries are those individuals and organisations involved in the marketing and promotion of the arts (Kubacki and O'Reilly, 2009). As an occupation that mediates between the fields of production and consumption in the subsidised cultural sector, arts marketing has become professionalised in a manner analogous to that described by Bourdieu (1984, p. 359) for the occupations of the "new petite bourgeoise" involved in the presentation, representation and provision of symbolic goods and services. Situated between cultural production and cultural consumption, the purpose of arts marketing is to communicate the value of specific forms of cultural production to the audience (the market) to stimulate their cultural consumption. This process drives specific business outcomes according to organisational objectives (be they artistic, financial, social or a combination of the three) and operates in the wider context of cultural policy discussed above.

Arts marketing can be considered as a managerial tool (Venkatesh and Meamber, 2006) to promote cultural goods. On the other hand, it is an "integral element of artistic production" (Butler, 2000, pp. 345-346) which combines "value-defining, value-developing and valuedelivering processes [in order to] capture the essential design-production-delivery processes in the [art] field". Thus, arts marketing aims to adjust the process and the product of artistic creation to be able to satisfy the market/the audience. According to Butler (2000), there is a three-step process of value creation: defining, developing and delivering value (for a discussion on the dynamics of a value generation in contemporary arts, see Rodner and Thomson, 2013). All steps are equally important and include both aspects of cultural production and consumption. Butler (2000, p. 354) emphasizes that,

In the arts, "value", or "worth" is not at all as clear cut as in business, since there is no consensus on criteria [...] However, at the "pure" level, the very notion of art for art's own sake determines that the artist is the ultimate or only arbiter of value.

There are then two main theoretical methods of marketing applied in the arts: the "productled" approach, focusing on the product and the segment of the population best suited for it (Kawashima, 2006) and the "market-led" approach in which organisations reorient themselves around the needs and desires of their audience and commit to the continuous creation of value for audience (Lee, 2005a; Kemp and Poole, 2016). Many researchers note that arts marketing has customarily used the former rather than the latter (Kawashima, 2000; Kolb, 2000; Colbert et al., 2004) based on the Romantic idea that artistic production must remain independent from external forces to preserve its value (Lee, 2005a). Lee (2005b) is concerned with the incompatibility of commercial marketing concepts with the idea, inherent in arts subsidy (if not in the arts per se) that the product, i.e. the artefact or object of artistic production, is sacrosanct. While this ideological viewpoint runs counter to the central tenet of marketing theory, namely, being market-led, the specificity of artistic production has long been acknowledged (see Hirschman, 1983).

By necessity, the policy model of the democratisation of culture entails a product-led approach to audience (Kawashima, 2000; Bjørnsen, 2011). The consumer orientation of the marketing concept - that is to say, the assumption of consumer primacy as the central normative point on which marketing operates - remains sufficiently strong for Brown (2002, p. 320) to argue that "The option of being a non-customer orientated "marketing" organisation is precluded on principle, if not in practice". Indeed, one might argue that the very premise of public subsidy is that the arts remain product-led. According to a market(ing) 
orientation, an "organisation should produce what its customers really need rather than struggling to sell what it can produce" (Lee, 2005b, p. 291). As Diggle (1994, p. 256) notes, "Commercial marketing cannot tolerate the notion of having product that is out of control. Arts marketing accepts this as part of the territory". The seemingly paradoxical situations which arise from this philosophical bias are discussed extensively by Kolb (2000) and accurately summed up by Butler (2000, p. 343),

There can be few management scenarios in which a marketing executive would choose not to have a major input into product design; in which the producer would disregard market preferences in the interests of product quality and integrity, and in which a successful product would be withdrawn in favour of a certain loss-maker. While such oddities would confound most marketers, they are common in marketing the arts.

In the arts and cultural sector production pre-empts demand, which provides a challenging context for arts marketing in comparison to other disciplines (Colbert et al., 2004). The essentially oxymoronic nature of arts marketing is also identified by Lee (2005b, p. 3) when she identifies the explicit tension "between the customer orientation of the marketing notion and the Romantic view of artistic production". Yet as Wickham et al. (2020, p. 83) identify, while there is some overlap between the marketing concept and arts/cultural production (in terms of planning and strategy), "it is widely acknowledged that the idiosyncratic nature of the arts and cultural sectors, where co-creation and artist-led product development are the norm (rather than the exception), does not fit easily into mainstream marketing theory". Cocreation concerns the processes of collaboration between consumers and producers in creating value in a co-consuming brand community (Pongsakornrungsilp and Schroeder, 2011) of which there are a significant number in the cultural sector (for a detailed overview of socio-culturally informed value creation in the visual arts see Preece et al., 2016).

The policy context within which arts marketing operates is, then, one of a tension between a set of universalist values considered implicit within Western aesthetics on the one hand and, on the other, the socially stratified consumers of cultural organisations (Bennett, 2017); this tension between the ideological and the organisational is explored in depth by Hadley (2021). Given that, as Butler (2000) notes above, arts marketing (or audience development) may be considered to involve "value-defining, value-developing and value-delivering" processes, a key element of the Modern Fairies project was the investigation of whether these value-adding processes might be undertaken at the point of remediation, rather than at the stage of intermediation.

\section{The Modern Fairies project}

The AHRC-funded Modern Fairies project was a large-scale collaboration between songwriters, musicians, artists, poets, filmmakers and academics to research the intangible heritage culture of British folk tales (for an extended description of the project, see Hield et al., 2021). The project examined how individual artists approach archival materials and the strategies audience use to engage with such (familiar and new) material and what kinds of contextual framing might help them. In response to viewing a series of works-in-progress, the research element of the project explored how these remediations intersected with audience sense of regional, social and individual identities. To achieve this, the artists were not only commissioned to create but also to reflect on their process to interrogate established practice and explore the impacts of collaborative and cross-artform ways of working. Sage Gateshead and Soundpost (project partner organisations) helped design and shape activities, hosting rehearsals, public work-in-progress "Gatherings", foyer exhibitions and workshops. Of primary focus in the project was how archival folkloric material could be made relevant to contemporary audience via a researched and exploratory process of artistic re-mediation.
Practices of production and consumption

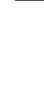


AAM 11,3

\section{6}

The structure of the project sought to place creativity in a social context by involving current and new audience in a process designed to remediate heritage culture.

For Bolter and Grusin (1999) - whose own work was a remediation of the earlier theories of Marshall McLuhan (1964) - the history of media (or perhaps platforms) should not be understood as a series of displacements in which new (e.g. internet) replaces and makes obsolete old (e.g. radio). Rather, new media transform older media, retaining some of their features while discarding others. As such, remediation is "the way in which one medium is seen by our culture as reforming or improving upon another" (Bolter and Grusin, 1999, p. 59), such that "... a newer medium takes the place of an older one, borrowing and reorganizing the characteristics of writing in the older medium and reforming its cultural space" (Bolter, 2001, p. 23).

Within the context of the Modern Fairies project, the specific purpose of remediation was to make archival material relevant for contemporary audience. A key objective of the project was to engage non-attenders (designated as being market segments who were either new to the venue hosting the project performances (Sage Gateshead) or new to the predominant artform of the project (folk music). This, then, was a process of both remediation and intermediation, designed to both "borrow" and "reorganise" archival folkloric material to "reform its cultural space" via processes of both artistic creation and arts marketing in an attempt to engage new audience.

The creative context of the Modern Fairies project placed both implicit and explicit boundaries on the autonomy and agency of the contracted artists. For example, in remediating the thematic source content provided via academic archival research at the outset of the project, the artists had a personal choice regarding their level of engagement with the structural socio-economic injustice and precarity that predominate in our present historical moment (for example in considering how the sociological dimension of fairy and folk tales can be extrapolated from existing metaphor to address e.g. the refugee crisis). As one artist noted,

The thing that makes it interesting for me-as a girl who came out of the working class-is that these are stories about outsiders, though they're full of kings and queens the heroes are often the poor figures who come in and achieve things despite their outsider status. So I think there is a way of approaching this by remembering that this is in a sense working-class literature, working-class tales. These are tales of the people and of the land, so providing we don't present them in too high culture a way that artificially separates them from people's lives I think it should be possible. It's worth finding out.

Such boundaries also challenged their sense-of-self as artists and (via the academic research process) questioned their relationship to audience/the market. This critical examination of the producer-consumer relationship was a key element of the research framework, which sought to understand how a curated set of folkloric material might be re-mediated for both current and potential audience demographics.

Key to this process was the attempt to enhance the audience "experience and interpretive capabilities" (Walmsley, 2016, p. 70) via the process of remediation. In selecting and reflecting upon archival material, and then remediating the material within contemporary idioms, the artists worked as cultural intermediaries, undertaking the role of developing the audience's interpretive capabilities via insights into work-in-progress and by providing direct online access to the creative process. Such processes may allow some barriers to engagement to be circumvented while increasing motivation to participate via "bi-directional" communication (Crawford et al., 2014 cited in Walmsley, 2016, p. 69). Hall's (1980) encoding/decoding paradigm, which understands consumption as an active process, has enabled a wide array of ethnographic research of specific audience groups to explain how social determinants influence the decoding process. In the context of the Modern Fairies project, a key 
determinant of the decoding process for both traditional and new audience was prior, often life-long, engagement with and an emotional and/or intellectual attachment to, folklore (Hield et al., 2021). The often unconsciously pervasive role of folk lore, myth and fairy tales in our childhoods, and to a lesser extent adult lives, provides a reservoir of affective material to facilitate interpretive capabilities and drive bi-directional communication.

\section{Sense-of-self-as-artist}

The way an artist is paid profoundly affects his product. At one extreme he sells what he has already made, at the other he is paid in full before he starts making anything - that is he is commissioned, he is paid in advance. It is this second mode of payment that goes to the recipient of state subsidies. An artist in that position is relieved of the pressure to please the public, the audience, and is free to court the approval of an inner circle of colleagues, critics and experts to be self-indulgent. One quotation summarises a large part of it. Arnold Schoenberg, who started atonal composition in 1908: "I believe that a real composer writes for no other purpose than to please himself. Those who write because they want to please others, who have audiences in mind, are not real artists" (Amis (1989) quoted in Pick and Anderton, 1996, p. 19).

The above quote from Kingsley Amis usefully captures a number of themes that arose in the course of the research interviews and which will be discussed here. These themes were of both a practical and a philosophical nature, and the research process, undertaken over many months and at varying stages within the project development, was able to investigate how the ongoing processes of remediation and intermediation were addressed by the project artists, both as individual factors and as a complex web of interlocking concerns. A key determining factor was the nature of the process of artistic production, and how the artists saw their agency and role within that process. As Amis identifies, the material construct of the process - namely, whether it is a commission, or an attempt to sell a product post-creation - has a significant impact on the sensibilities which the artist brings to the work:

Obviously there are certain projects where you would, you are thinking about the end product, and who it's for, the audience, but that would be on specific projects rather than anything that I would just write from my own, you know, initiative.

But then artists will say that they want this freedom to express however they wish...

it's different what each thing is meant to be in everyone's heads, and if you said it was actually meant to be more of a kind of conversation then people might go into it differently.

Alongside the structural tension between the need to think about the end product (commission) as opposed to the sense of freedom in working solely to one's own ends (selling what is already made) is the sense that the materiality of the presentation/performance context determines whether the artists is in a professional mode:

Several of these musicians have said to me- "Although it's going to be a work-in-progress I need it to be as polished and as representative of me as an artist as possible."

But then some people were always going to think, "Well, it's a stage. I'm doing a gig." Presenting something that's half-finished is always un-nerving because we're trained to deliver something that people have paid for their tickets for, you know... So anything that's audience-led or involves them

I'm always a little bit hesitant to be involved.

The methods used in the research process enabled an assessment and interpretation of the behavioural ramifications of the artists' sense-of-self. Simultaneously, the participation in the project of academics and authors with expertise in the topic field created power dynamics which the artists needed to reconcile with their own sense-of-self as autonomous and selfdetermining individuals as regards the process/act of creation. 
AAM 11,3

\section{8}

It is clear from the interviews that the project artists felt "normatively permitted" (Hirschman, 1983, p. 48) to place a higher priority on self and peer evaluations (as happened continuously throughout the project duration) than upon any contingent ideas of future commercial success. That such an identity-based perquisite still pertains in the data from this project is indicative of the manner in which the value orientation of the Modern Fairies artists was generally perceived as "the differentiation between 'artistic creativity' and 'commercial creativity" (Hirschman, 1983, p. 47). As Røyseng et al. (2007, p. 1) noted in their study of young Norwegian artists, even in situations where the contexts for artistic work have changed substantially over several decades, the charismatic myth of the artist - "that artistic work should be carried out in a disinterested manner with a pure aesthetic vision as the only guiding light" - remains a core idea and an important reference point in the construction of professional cultural identities. For many of the artists, their sense-of-self (their "selfconceptualisation as artists") retained strong elements of Romantic discourse, with transcripts showing adherence to determinedly subjective aesthetic ideals:

I hate the idea that I would be making something purely to sell things.

I think for the artist to me that spark's gone if we have to do work for mass consumption and I don't think any artist wants to do that.

But there's also that thing about trying to write, trying to predict what somebody would like and that's kind of like a fool's errand really and you won't write in your own true voice you know if you try to predict what will be popular or what will. . . You have to be true to yourself and write what you really feel and then hope there is a response to that.

Yet this sensibility was, in most instances, tempered with pragmatic economic concerns and everyday realities, with research discussions showing a clear belief in the causal relationship between financial precarity and compromised artistic ideals. An interesting delineation that arose in the discussions on audience detailed below was connected not only to the artists' sense-of-self but also to implicit and explicit perceptions of their career. These perceptions ranged from being an "Artist" producing "art for art's sake" in splendid isolation from the world and its commercial considerations to the idea of "making a living" expressed here:

I think it's the making a living bit is the reality of being a creative person and a musician. It's about respect that without an audience. . . you haven't got anything really. Without you they don't have a night out and vice versa unless you're playing for yourself. But I think there's a point at which you indulge, I guess, your own creative urges.

There is a long-standing commentary around the tension between artistic and commercial imperatives, which more recently has been argued to be a result of the increasing hegemony of the corporate model associated with the growth of managerialism in the subsidised arts (Harrison, 2009). Indeed, within the project data a straightforward "denial of the economy" (Bourdieu, 1993, p. 50; Abbing, 2002, p. 48) was rarely evident. As Fillis (2006) argues, the commercial merits of being prepared to ignore market demand and customer wishes are long-standing in a rage of artform sectors, where product and artist centred marketing have been successful. Questions of passion, dedication and authenticity were evident in the data alongside a sense that ambiguity as regards the denial of financial motives was contingent upon who was asking the question - that is to say, who was the audience:

I mean I'm sure the idea of the audience is in there somewhere but I don't feel like I've been aware of that. I think I've just been trying to figure out me as an audience of this, you know. . . I realise I can't really write unless I'm writing from a first-person and from my... writing honestly about something so l've just been trying to get to that point where I can write about something with authority so yeah I haven't really been thinking about an audience. 
With the context of the Modern Fairies project having a dual research/creative focus - within which the artists were commissioned to work to a specific research brief - the artists were involved in a continual process of negotiation. The context placed both implicit and explicit boundaries on the artistic autonomy and individual agency of the contracted artists, challenging their own sense-of-self as artists and also (via the academic research process) questioning their relationship to audience/the market.

\section{Relationship to the audience (as market)}

Well, I don't. I don't. Unless I'm told I have to. I do not think about an audience. Because it would stifle my creativity.

So I think when I first get an idea I don't have an idea about audience particularly but I suppose as the idea develops I reach a stage where I want to share it with people

The spectrum of sensibilities as regards how the project artists saw themselves was shown in the data to be in a symbiotic relationship with how they conceived of, and understood/ enacted, their relationship with the audience. While for some audience response was never a concern, even as regards feedback loops intentionally built into the project architecture and discussed below, for others the relationship with the audience was situated in the conceptual space between production and consumption:

From my point of view you didn't necessarily create art with the audience necessarily in mind, but you definitely wanted to see how those things worked together with the audience.

The more pragmatic of the artists also readily identified with the fact that, alongside the commercial concerns discussed earlier, audience engagement is a key component of the production and consumption process:

It's an ideal to be able to put all notions of audience and commerciality out of your head when you're writing. . . but it's not necessarily "selling out" to say that in some projects the audience reaction is actually some people you are taking into consideration as part of your "creative juice" in a positive way.

There is also the recognition that contemporary notions of artistic legitimacy and the status of works of art are highly historicized, such that work which was previously produced to order, by writers and musicians trying to make a living (and without the state subsidies which Amis references) has now been elevated to the canon of high art:

But we were talking. . . about the likes of Dickens and Bach you know and they were just churning it out it was a different kind of set-up, probably the sense of artist was in there somewhere but it was very much a sense of "we need these for the church service on Sunday" and Dickens having to churn out his newspaper publications it's quite a different thing you know it almost feels like the artistry is reduced by the fact that you're very much writing it to commercial order but with hindsight you look at those people and you go "they're incredible".

The relationship to the audience, and to the process of consumption, also triggered reflection on the nature of the audience. A concern in the research interviews was in relation to the social stratification of cultural consumption regarding (in particular) folk music as an artform:

the one thing, whatever it is, you look at the audience firstly it's predominantly white always, that's not to say that the people on the stage are white, but it's still a white audience, the other thing to notice it's probably more blokes than women, and the average age I'd say goes from mid-40s up

I imagine my audience in my own image. So there's pretty hideous assumptions there that mine are white middle class audience cause that's what I know of that artform being in and I've never actively tried to write and communicate with someone who isn't essentially me in my own head.

Practices of production and consumption 
AAM 11,3

\section{0}

Given that engaging new audience (via making the source material "modern") was a key research objective of the project, queries were raised around how the role of the artists - as potential intermediaries in both the production and consumption of the new material - might enable new audience to engage with the project:

It's an interesting idea isn't it that the people who don't come are kind of intimidated because they see it as a clique even though it might be very welcoming but the perception. . . I would have thought one of the things this project wants to do is try and break through those...

Though I've worked with this material for years I've worked in an area that self-selects for audience. People who are inclined to be interested in this sort of thing find the work that I do, and that the people I work with do. But this idea of bringing fairies to audience who have absolutely no interest in them whatever and changing their minds, helping them to see that there is relevance in these old tales for people now. Whether we succeed or not I don't know but the attempt is interesting and worthy.

An interesting aspect of the framing of the archival material and which relates both to the idea of enhancing the audience's "experience and interpretive capabilities" (Walmsley, 2016) and that of bi-directional communication was the audience prior engagement with, and subsequent attachment to, the source material (either thematically or specifically). As Brown and Novak (2007, pp. 10-11) identified, there is a positive correlation between audience anticipation and captivation, defined as a "positive expectation" or condition of "readiness-toreceive". Within a project like Modern Fairies, with a complex and in-depth narrative hinterland, there was a clear recognition from the artists that some form of intervention was required:

You know people are gonna think that they know what they're coming to see but unless they've actually researched it and found the local material that we've found they aren't gonna have that information.

While audience engagement can be enhanced by pre-performance activities - such as the provision of online materials via the Modern Fairies website and foyer exhibitions at Sage Gateshead - this type of "educative context" (Pitts, 2005, p. 264) can come into tension with the audience's prior affective relationship with the project source material. This tension was noted by the artists when the audience feedback began to reveal that audience members had prior knowledge of the material being remediated:

... sometimes you just play to certain people, disappear, I mean, you don't hear anything. But hearing the feedback is quite interesting. And then that thing that you said about me saying, "No, don't touch my stories. They mean a lot to me." I mean, I'll go away with that now. That will be part of my considerations for any future project

Within the folk music genre - which is heavily dependent on self-referentiality and the reinterpretation of old material - this response is especially resonant. A key function of the artistas-intermediary role within the project was to assimilate audience feedback at multiple stages in the process of production, to mediate and evolve the process of consumption to add those "valuedefining, value-developing and value-delivering" processes (Butler, 2000). Inevitably, this proscribed element of the commission found itself in contestation with the artists' sense-of-self.

\section{Audience feedback and response}

A point of tension within the project was between the stated aim of using audience feedback to iteratively inform the final process of consumption, as against the (frequent) refusal of the artists to consider that such feedback had a role to play in their own creative production,

I think I have to be honest here and say I'm not sure that I changed any of my own work in direct response to audience feedback. 
Honestly, I felt I wasn't that aware of audience feedback after the Sage gigs. My approach to it was to try to give the best interpretation of our work on stage and treat it as I would any performance and hopefully leave the audience with space to absorb and take home.

This issue is connected to an expressed lack of clarity around the project artistic brief, whereby artists felt that they were simultaneously being asked to work to a commission and to freely explore their responses to the source material. Their uncertainty ("I don't know") is evident:

I don't know that I did respond directly to audience feedback during the process, except that I was really conscious that we had to keep coming back to the word "modern". . . because some focus group members had commented that they wanted a more contemporary feel.

I don't know how much audience feedback was already in place before the final performances but I don't feel like I'd been specifically directed to it (that might just have been me missing an email) or that it was as important as the feedback/collaborations between the artists themselves.

The implications of cultural capital and artistic disposition for professional credibility (Smith Maguire, 2015) are evident in the expression of where cultural capital lies within definitions of how the artists self-referentially define their "audience" as an insider group, who require a degree of cultural capital to have an opinion which is both informed and (therefore) of value. The data shows here how Hirschman's (1983, p. 48) idea of being "normatively permitted" noted in the earlier discussion on sense-of-self-as-artist - enables the project artists to place a higher priority on self and peer evaluations:

I don't find public feedback helpful. . .in fact, the opposite, it can take your confidence away. I personally prefer to work out ideas among fellow artists, not the general public. If "public engagement" prior to the work being in closer-to-finished state is really necessary, I'd prefer to show it and discuss it with other people in the arts: students studying song-writing or fantasy/myth/ folklore-inspired writing for example. People who understand what the creative process is, what raw work looks like, and can respond in more useful ways.

While in the project conception, the feedback loop process was envisioned as enabling a process of reciprocal and reflexive learning, operational issues and resource constraints combined with the complex issues outlined above led to a diminished role for audience feedback. Nonetheless, it was evident that a number of the artists - most specifically those involved in public performance on a regular basis - had undertaken considerable reflection as part of the project,

I've also had to redefine what an audience means to me, as I've become used to an audience that sits, listens, and occasionally applauds. Although performance isn't the entire focus of a singer/ songwriter, I'm used to receiving direct feedback from the audience. This project is challenging me to think differently about how I present songs in my own work.

The material practice of the artist-as-cultural-intermediary in the framing or qualifying of goods (e.g. as "legitimate" or "authentic") was, for the artists engaged in the Modern Fairies project, also deeply connected to ideas of loyalty to the consumer and to one's own artistic process:

If you build a loyal fan base you have respect for your audience. I think some people really lack that. And part of that is not giving them what they want because that's not their job to dictate to you what you should be doing.

It is of course interesting to hear how a given piece of work is received by an audience. But there are a lot of sides to this discussion, for example if you take feedback and change your performance or piece of work, then the creator of that feedback is then having a hand in the creation, or change of the piece of art they initially came to see.

\section{Practices of production and consumption}

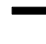


AAM 11,3

Cultural intermediaries have an impact with regard to the production and reproduction of markets. Seen through this lens, a key objective of the project was to produce both "discrete and concrete engagements with and between goods and individuals" and to "construct new meanings of goods/practices and their value" (Mathews and Smith Maguire, 2014, p. 10) such that:

As an artist it was always a difficult element of this project that technically there was no finished final outcome to the pieces created, e.g. tour, album etc. Audience feedback is difficult if what one is presenting isn't a final version, as one is generally aware of the flaws already or else it would be finished.

As noted above, tension was evident regarding the post-project life of the artistic products and their wider viability in the market - a significant focus for artists and producers in intermediary roles - rather than the capacity of the work to fulfil the research objectives of the project.

In terms of bringing new audience into subsidised cultural spaces, it becomes important to consider the extent to which the artist-as-cultural-intermediary can pose any substantive challenge to traditional models of "power, position, privilege and patronage" (Negus, 2002, p. 513) which keep certain demographics away from concert halls and opera houses. As has been discussed in this paper, the subjective dispositions of the commissioned project artists were key both to delivering on, and deviating from, the project objectives. As Bourdieu (1984, p. 238) argued, there is a significant degree of connection between cultural intermediaries' occupations (in the case of the Modern Fairies project artists, writers, poets and musicians) and any given individual practitioner's habitus, an array of cultural capital and subjective dispositions. These "elective affinities" - a perceived harmony between personal tastes and professional function and position - mean that "cultural intermediaries are both cultural producers and their own ideal consumers" (Smith Maguire and Matthews, 2010, p. 408). In typifying their market, the cultural intermediary is thus also well placed to understand and direct it. As a result, cultural intermediaries do not experience their work as an instrumental calculation ("selling out") because it is an expression of their own tastes and dispositions as artists.

\section{Conclusion}

In thinking widely about artistic production in the creative industries, it is evident that processes of cultural production function amidst the polarities of "creativity" and "commerce" (Hesmondhalgh, 2005). The research detailed in this paper considered artists as "cultural intermediaries", i.e. as actors occupying the conceptual space between production and consumption in an artistic process. In selecting and reflecting upon archival material, and then remediating the material within contemporary idioms, the artists worked as cultural intermediaries, undertaking the role of developing their audience interpretive capabilities.

A key finding of the research was the cognitive and/or creative dissonance within the adopted subjective disposition of "the Artist" and between the Romantic idea that artistic production must remain independent from external forces to preserve its value and a consideration of market need/demand. The oxymoronic nature of arts marketing, and the resulting tension between the customer orientation of the marketing notion and the Romantic view of artistic production, created the material and conceptual space within which the artistas-intermediary operates. The artist-as-intermediary role, at the intersection of culture and economy, undertaking creative processes to mediate how goods are perceived by others enables these value-adding processes to be undertaken at the point of remediation rather than at the stage of intermediation. 
This study questions the conceptual boundaries of the cultural intermediaries concept, and its potential roles in both audience development and artistic production. In seeking to make relevant the origin stories used in the project, further research would be required to assess whether, through their "symbolic imposition" (Bourdieu, 1984, p. 362) of meanings, the artists-as-cultural intermediaries frame goods and practices so that they appear to the audience to "go together" with his or her taste (Bourdieu, 1984, p. 232). In considering the socially constructed boundaries between legitimate and illegitimate culture (Bourdieu, 1996) and the role of the Modern Fairies project artists as cultural intermediaries, future research might consider the contested construction of cultural legitimacy in the context of "Disneyfied" popular culture images of fairies. Part of the function of the process of remediation might then be seen as an attempt to recuperate tales about fairies and to reposition them as "legitimate" culture in a "modern" context.

In retrospect, the conceptual dialogue between the independent "artist-as-artist" versus the commissioned "artist-as-producer" within the Modern Fairies project unearthed a range of interconnections and tensions which were not able to be fully explored within the research limitations. Nonetheless, it is evident that when artists are engaged in a process of remediation which has a distinct audience development focus, they do also begin to intermediate between themselves and the audience/consumer. Further research should further investigate the audience development benefits of the artistic value co-creation process by considering whether audience gain additional benefits from this form of interaction to draw a richer picture of how (both commercial and subsidised) cultural audience engage with value creation in the context of artistic production. Pongsakornrungsilp and Schroeder's (2011) work on understanding value co-creation in a co-consuming brand community is valuable in developing an ongoing research agenda. Through analysis of an online fan community, they offer insights into how consumers co-create value via interaction, within the context of brand communities. They show the dynamic roles consumers play in the value co-creation process as providers and beneficiaries - co-creating value for themselves, brand communities and organisations.

In the Modern Fairies project, artist perceptions of their role were determined by the subjective disposition required by the market context in operation at the time (in the case of this project, as commissioned artists working to a brief). Their ability (and indeed willingness) to engage in this process, however, was to a great extent proscribed by their "sense-of-self-asartist". In considering the Modern Fairies project artists as "professionals of qualification", future research should investigate how this process of qualification is both rendered conflicted by and is contingent upon, subjective conceptualisations of their sense-of-self-as-artists as opposed to a Bourdieusian sense of market-oriented professionalism. The extent to which artists as cultural intermediaries can be conceived as market actors is contested by a refusal of the commercial ethos - a denial of the economy - within their own subjective dispositions.

\section{References}

Abbing, H. (2002), Why are Artists Poor? The Exceptional Economy of the Arts, Amsterdam University Press, Amsterdam.

Becker, H.S. (1982), Art Worlds, University of California Press, London.

Bell, D. and Oakley, K. (2015), Cultural Policy, Guilford Press, New York.

Bennett, T. (2017), "Exhibition, truth, power: reconsidering "the exhibition complex", in Latimer, Q. and Szymczyk, A. (Eds), TheDocumenta 14 Reader, Prestel, Munich, pp. 339-352.

Bennett, T., Savage, M., Silva, E., Warde, A., Gayo-Cal, M. and Wright, D. (2009), Culture, Class, Distinction, Routledge, London and New York.
Practices of production and consumption 
Bilton, C. (2017), The Disappearing Product: Marketing and Markets in the Creative Industries, Edward Elgar, Cheltenham.

Bjørnsen, E. (2011), The Limitations of Audience Development, Audiences Norway, Bergen, available at: http://artsandaudiences.com/wpcontent/uploads/2011/05/1449_bjornsen_110525_o1.pdf (accessed 20 October 2014).

Bolter, J.D. (2001), Writing Space: Computers, Hypertext, and the Remediation of Print, 2nd ed., Lawrence Erlbaum, Mahwah, NJ.

Bolter, J.D. and Grusin, R. (1999), Remediation: Understanding New Media, MIT Press, Cambridge.

Bourdieu, P. (1984), Distinction: A Social Critique of the Judgement of Taste (translated by Nice, R.), Routledge, Oxon.

Bourdieu, P. (1993), The Field of Cultural Production, Polity Press, Cambridge.

Bourdieu, P. (1996), The Rules of Art, Polity Press, Cambridge.

Brown, A.S. and Novak, J.L. (2007), Assessing the Intrinsic Impacts of a Live Performance, WolfBrown, San Francisco.

Brown, S. (2002), "Vote, vote, vote for Philip Kotler", European Journal of Marketing, Vol. 36 No. 3, pp. 313-324.

Butler, P.D. (2000), "By popular demand: marketing the arts", Journal of Marketing Management, Vol. 16 No. 4, pp. 343-364.

Callon, M., Meadel, C. and Rabeharisoa, V. (2002), "The economy of qualities”, Economy and Society, Vol. 31 No. 2, pp. 194-217.

Colbert, F., Nantel, J., Bilodeau, S. and Rich, J.D. (2004), Marketing Culture and the Arts, 2nd ed., HNC, Montreal.

Crawford, G., Gosling, V., Bagnall, G. and Light, B. (2014), "Is there an app for that? A case study of the potentials and limitations of the participatory turn and networked publics for classical music audience engagement”, Information Communication Society, Vol. 17 No. 9, pp. 1072-1085.

Diggle, K. (1994), Arts Marketing, Rhinegold, London.

Fillis, I. (2006), "Art for art's sake or art for business sake: an exploration of artistic product orientation", The Marketing Review, Vol. 6 No. 1, pp. 29-40.

Fillis, I. (2011), "The evolution and development of arts marketing research", Arts Marketing: An International Journal, Vol. 1 No. 1, pp. 11-25.

Hadley, S. (2021), Audience Development and Cultural Policy, Palgrave Macmillan, London.

Hadley, S., Hield, F. and Larrington, C. (2021), "Heritage culture and artistic reciprocity: remediating the mythical", in Maloney, L. and Schofield, J. (Eds), Music and Heritage: New Perspectives on Place-Making and Sonic Identity, Routledge, London.

Hall, S. (1980), "Encoding/decoding", in Hall, S., Hobson, D., Lowe, A. and Willis, P. (Eds), Culture, Media, Language, Working papers in cultural studies, 1972-79, Routledge, London, pp. 117-127.

Harrison, P. (2009), "Evaluating artistic work: balancing competing perspectives", Consumption Markets and Culture, Vol. 12 No. 3, pp. 265-274.

Harrison, A. (2016), "David Bowie: back in the spotlight, still refusing to play along", The Guardian, 2 January, available at: https:/www.theguardian.com/music/2016/jan/02/david-bowie-profileblackstar-album-release-8-january.

Hesmondhalgh, D. (2005), "The production of media entertainment”, in Curran, J. and Gurevtich, M. (Eds), Mass Media and Society, Hodder Arnold, London.

Hesmondhalgh, D. (2006), "Bourdieu, the media and cultural production", Media, Culture \& Society, Vol. 28 No. 2, pp. 211-231. 
Hield, F., Larrington, C., Hadley, S. and Price, S.M. (2021), "The obscure becomes vivid: perspectives on the remediation of fairylore by folklorists, performers and audiences", Revenant, available at: http://www.revenantjournal.com.

Hirschman, E.C. (1983), "Aesthetics, ideologies and the limits of the marketing concept”, Journal of Marketing, Vol. 47, pp. 45-55.

Holbrook, M.B. (1981), "Introduction: the aesthetic imperative in consumer research", in Hirschman, E.C. and Holbrook, M.B. (Eds), Symbolic Consumer Behaviour, Association for Consumer Research, Anne Arbour, MI.

Holbrook, M.B. and Zirlin, R.B. (1983), "Artistic creation, artworks and aesthetic appreciation: some philosophical contributions to non-profit marketing”, in Belk, R. (Ed.), Nonprofit Marketing, Vol. 1, JAI Press, Greenwich, CT.

Kawashima, N. (2000), "Beyond the division of attenders vs. non-attenders: a study into audience development in policy and practice", available at: http://wrap.warwick.ac.uk/35926/1/WRAP_ Kawashima_ccps_paper_6.pdf (accessed 8 January 2021).

Kawashima, N. (2006), “Audience development and social inclusion in britain”, International Journal of Cultural Policy, Vol. 12 No. 1, pp. 55-72.

Kemp, E. and Poole, S.M. (2016), "Arts audiences: establishing a gateway to audience development and engagement", The Journal of Arts Management, Law, and Society, Vol. 46 No. 2, pp. 53-62, doi: 10.1080/10632921.2016.1150929.

Kolb, B.M. (2000), Marketing Cultural Organisations: New Strategies for Attracting Audiences to Classical Music, Dance, Museums, Theatre and Opera, Oak Tree Press, Dublin.

Kubacki, K. and O'Reilly, D. (2009), "Arts marketing", in Parsons, E. and Maclaran, P. (Eds), Contemporary Issues in Marketing and Consumer Behaviour, Elsevier, Oxford.

Lee, H.-K. (2005a), "Rethinking arts marketing in a changing cultural policy context", International Journal of Nonprofit and Voluntary Sector Marketing, Vol. 10 No. 3, pp. 151-164.

Lee, H.-K. (2005b), "When arts met marketing: arts marketing theory embedded in Romanticism", International Journal of Cultural Policy, Vol. 11 No. 3, pp. 289-305.

Mathews, J. and Smith Maguire, J. (2014), "Introduction: thinking with cultural intermediaries", in Smith Maguire, J. and Mathews, J. (Eds), The Cultural Intermediaries Reader, Sage, London.

McLuhan, M. (1964), Understanding Media: The Extensions of Man, McGraw Hill, New York.

Miles, A. and Sullivan, A. (2012), "Understanding participation in culture and sport: mixing methods, reordering knowledges”, Cultural Trends, Vol. 21 No. 4, pp. 311-324.

Modern Fairies (2020), available at: www.modernfairies.co.uk.

Musgrave, G. (2015), "Cultural intermediaries and how artists get heard", available at: https:/www. create.ac.uk/blog/2015/03/18/cultural-intermediaries-and-how-artists-gets-heard/ (accessed 8 January 2021).

Negus, K. (2002), "The work of cultural intermediaries and the enduring distance between production and consumption", Cultural Studies, Vol. 16 No. 4, pp. 501-515.

O'Brien, D., Wilson, K. and Campbell, P. (2011), "The role of cultural intermediaries", available at: https://www.dropbox.com/s/nyv0pvxeuz917of/Apr\%202011\%20Cultural\%20Intermediaries. pdf?dl $=0$ (accessed 20 April 2021).

Pick, J. and Anderton, M. (1996), Arts Administration, 2nd ed., Routledge, London.

Pitts, S.E. (2005), "What makes an audience? Investigating the roles and experiences of listeners at a chamber music festival", Music and Letters, Vol. 86 No. 2, pp. 257-269.

Pongsakornrungsilp, S. and Schroeder, J.E. (2011), "Understanding value co-creation in a coconsuming brand community", Marketing Theory, Vol. 11 No. 3, pp. 303-324.

Preece, C., Kerrigan, F. and O'Reilly, D. (2016), "Framing the work: the composition of value in the visual arts", European Journal of Marketing, Vol. 50 Nos 7/8, pp. 1377-1398. 
AAM 11,3
Rodner, V.L. and Thomson, E. (2013), "The art machine: dynamics of a value generating mechanism for contemporary art", Arts Marketing: An International Journal, Vol. 3 No. 1, pp. 58-72.

Røyseng, S., Mangset, P. and Borgen, J. (2007), "Young artists and the charismatic myth", International Journal of Cultural Policy, Vol. 13 No. 1, pp. 1-16.

Smith Maguire, J. (2015), "Cultural intermediaries”, The Wiley Blackwell Encyclopaedia of Consumption and Consumer Studies. doi: 10.1002/9781118989463.wbeccs084.

Smith Maguire, J. and Matthews, J. (2010), “Cultural intermediaries and the media”, Sociology Compass, Vol. 4 No. 7, pp. 405-416.

Smith Maguire, J. and Matthews, J. (2012), “Are we all cultural intermediaries now?”, European Journal of Cultural Studies, Vol. 15 No. 5, pp. 551-562.

Smith Maguire, J. and Matthews, J. (2014), The Cultural Intermediaries Reader, Sage, London.

Stevenson, D. (2013), "What's the problem again? The problematisation of cultural participation in Scottish cultural policy", Cultural Trends, Vol. 22 No. 2, pp. 77-85.

Ultee, C.W., Battenburg, R. and Ganzeboom, H.B.G. (1993), "Cultural inequalities in cross-national perspective: a secondary analysis of survey data for the 1980s", in Rigney, A. and Fokkema, D. (Eds), Cultural Participation: Trends since the Middle Ages, (Utrecht Publications in General and Comparative Literature), John Benjamins, Amsterdam, Vol. 31, pp. 173-192.

Venkatesh, A. and Meamber, L.A. (2006), "Arts and aesthetics: marketing and cultural production”, Marketing Theory, Vol. 6 No. 1, pp. 11-39, doi: 10.1177/1470593106061261.

Walmsley, B. (2016), "From arts marketing to audience enrichment: how digital engagement can deepen and democratize artistic exchange with audiences", Poetics. doi: 10.1016/j.poetic.2016. 07.001 .

Walmsley, B. (2019), Audience Engagement in the Performing Arts, Palgrave Macmillan, Basingstoke.

Wickham, M., Lehman, K. and Fillis, I. (2020), "Defining the art product: a network perspective", Arts and the Market, Vol. 10 No. 2, pp. 83-98.

Wing Chan, T. and Goldthorpe, J.H. (2007), "The social stratification of cultural consumption: some policy implications of a research project”, Cultural Trends, Vol. 16 No. 4, pp. 373-384.

\section{Corresponding author}

Steven Hadley can be contacted at: steven.hadley@nuigalway.ie

For instructions on how to order reprints of this article, please visit our website:

www.emeraldgrouppublishing.com/licensing/reprints.htm

Or contact us for further details: permissions@emeraldinsight.com 